\title{
ARTIGO

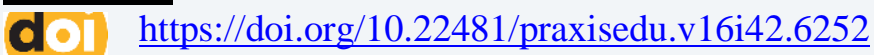

\section{PEDAGOGIA DAS CANOAS: MEMÓRIAS E HISTÓRIAS DAS MULHERES NEGRAS DA VILA DO CARMO DO MACACOARI-AP ${ }^{1}$}

\author{
PEDAGOGY OF CANOE: MEMORIES AND STORIES OF BLACK WOMEN FROM \\ VILA DO CARMO DO MACACOARI-AP
}

\section{PEDAGOGÍA DE LA CANOA: MEMORIAS Y HISTORIAS DE MUJERES NEGRAS DE VILA DO CARMO DO MACACOARI-AP}

\author{
Maria das Dores do Rosário Almeida \\ Instituto de Mulheres Negras do Amapá - Brasil
}

\author{
Elivaldo Serrão Custódio \\ Universidade Federal do Amapá - Brasil
}

\begin{abstract}
Resumo: Neste artigo, procurou-se compartilhar a Metodologia das Canoas, como possibilidade de (re)construir histórias e memórias esquecidas das mulheres negras da Vila do Carmo do Macacoari-AP nas historiografias e (re)contar novas histórias a partir de experiências de vida. Com base nos métodos qualitativo, descritivo (análise documental) e de pesquisa bibliográfica, tendo como referência a pesquisa-ação, abordaram-se as premissas da metodologia e descreveu-se também o caminho percorrido para estruturar as suas fases e interfases. Concluiu-se que a Metodologia das Canoas é uma ferramenta que pode ser aplicada em estudos científicos para desvelar sujeitos anônimos que vivenciaram histórias de suas comunidades, assim como contribuir para a preservação da memória de grupos, povos e comunidades tradicionais excluídos das historiografias.
\end{abstract}

Palavras-chave: Memória e história. Mulheres negras amazônicas. Pedagogia das canoas.

Abstract: In this article, we tried to share the Canoas Methodology, as a possibility to (re) build forgotten histories and memories of black women from Vila do Carmo do Macacoari-AP in historiographies and (re) telling new stories from life experiences. Based on the qualitative, descriptive (documentary analysis) and bibliographic research methods, with reference to action research, the premises of the methodology were addressed and the path followed to structure its phases and interfaces was also described. It was concluded that the Canoas Methodology is a tool that can be applied in scientific studies to unveil anonymous subjects who have experienced stories from their communities,

\footnotetext{
${ }^{1}$ Uma versão preliminar deste trabalho foi apresentada no $3^{\circ}$ Congresso Internacional Povos Indígenas da América Latina (CIPIAL): Trajetórias, narrativas e epistemologias plurais, desafios comuns. De 3 a 5 de julho de 2019, Brasília - DF, Brasil, com o título "Memória e história: pedagogia das canoas - encontro de experiências".
} 
as well as contributing to the preservation of the memory of groups, peoples and traditional communities excluded from historiographies.

Keywords: Memory and history. Amazonian black women. Canoes pedagogy.

Resumen: En este artículo, tratamos de compartir la Metodología de Canoas, como una posibilidad de (re) construir historias y recuerdos olvidados de mujeres negras de Vila do Carmo do Macacoari-AP en historiografías y (re) contar historias nuevas de experiencias de la vida. Con base en los métodos cualitativos, descriptivos (análisis documental) y de investigación bibliográfica, con referencia a la investigación en acción, se abordaron las premisas de la metodología y también se describió el camino seguido para estructurar sus fases e interfaces. Se concluyó que la Metodología de Canoas es una herramienta que puede aplicarse en estudios científicos para revelar sujetos anónimos que han experimentado historias de sus comunidades, además de contribuir a la preservación de la memoria de grupos, pueblos y comunidades tradicionales excluidos de las historiografías.

Palabras clave: Memoria e historia. Mujeres negras amazónicas. Pedagogía de canoas.

\section{Introdução}

"O silêncio significa voltar às minhas origens."

(Lao-Tzu)

Para Le Goff (2013, p. 22), a história é uma narrativa, podendo ela ser verdadeira ou não, com base em fatos reais ou fantasiosos. Segundo Le Goff (2013, p. 390), a memória coletiva pertence a quem tem poder, isto é, a reis e rainhas, pois “[...] os esquecimentos e os silêncios da história são o reflexo desses mecanismos de manipulação da memória coletiva". O autor diz que, analisando conceitos, se pode perceber que muitas histórias foram contadas de forma errada/equivocada e/ou desprovida de informações verídicas, pois, nesse processo, os protagonistas e suas memórias foram silenciados dominados ou soterrados, negando-lhes o direito de contar suas verdadeiras narrativas. Logo, podem ser recontadas por meio da memória histórica.

Portanto, o presente artigo procura mostrar como a Metodologia Pedagogia das Canoas pode contribuir para a preservação da memória de grupos, povos e comunidades tradicionais excluídos das historiografias.

O artigo foi desenvolvido com base nos métodos qualitativo, descritivo (análise documental) e de pesquisa bibliográfica, tendo como referência a pesquisa-ação, na visão de Barbier (2007). Para o autor, toda pesquisa-ação “... é singular e define-se por uma situação 
precisa concernente a um lugar, a pessoas, a um tempo, a práticas e valores sociais e à esperança de uma mudança possível" (BARBIER, 2007, p. 19).

Então, pretende-se trazer à luz a discussão de que, em uma metodologia científica, é possível aliar o rigor acadêmico com a criatividade, trazendo, como foco, a Pedagogia das Canoas, com suas singularidades próprias, centrada no acolhimento, perpassando por quatro premissas: o zelo, o respeito, a escuta ativa e o afeto. Uma metodologia que pode ser aplicada tanto a pequenos grupos de diferentes pessoas, 2 envolvendo, nesta pesquisa, diferentes mulheres, 3 quanto em diferentes campos dos conhecimentos das ciências humanas e sociais, possibilitando uma abordagem transversal.4 Com ela, pode-se trabalhar a etnografia e a memória histórica conjuntamente e acolher diferentes visões de mundo sobre o mesmo contexto histórico.

A Metodologia, a qual denominamos, neste artigo, de Pedagogia das Canoas, foi o percurso metodológico, com base na experiência das interlocutoras da pesquisa, para desvelar o pioneirismo das mulheres negras no território do Carmo do Macacoari5 e suas contribuições nos aspectos cultural, social e político, no qual se priorizou, como referência, a história oral. Logo, pode-se afirmar que a Metodologia das Canoas contribuiu para desvelar, a partir de entrevistas e rodas de conversas com 14 mulheres negras mais velhas6, que o pioneirismo de mulheres negras na Vila do Carmo do Macacoari7 se iniciou no final do século XIX, perpassando pelo direito à terra, pelo combate ao latifúndio e pelo seu protagonismo. Suas narrativas apontaram que, naquele território, havia duas categorias de mulheres negras pioneiras: as negras de posse, que eram as criadoras de gado; e as negras sem posse, as roceiras. (ALMEIDA, 2018).

\footnotetext{
${ }^{2}$ Ribeirinhos, jovens, quilombolas, entre outros.

${ }^{3}$ Mulheres negras criadoras de gado e mulheres negras roceiras.

${ }^{4}$ Gênero, raça, classe, cultura, meio ambiente, entre outras.

${ }^{5} \mathrm{O}$ estado do Amapá está situado no extremo norte do Brasil, na Amazônia brasileira. É formado por dezesseis munícipios, entre eles o munícipio de Itaubal do Piririm, onde está localizada a comunidade da Vila do Carmo do Macacoari, uma comunidade negra, tradicional, ribeirinha, descendente de negros escravizados que tem aproximadamente duzentos anos de existência. Lá vivem 97 famílias de acordo com o Relatório "Relação das Famílias: Estratégia da Saúde da Família da Unidade Básica de Saúde do Carmo do Macacoari no período de 2011 a 2016". O termo "vila" é o espaço geográfico onde se origina a comunidade de Carmo do Macacoari, concentrando grande parte dos moradores, órgãos públicos e privados, e será utilizado aqui para delimitar a área geográfica desta pesquisa.

${ }^{6}$ Mulheres negras, que, aqui, nos referimos como as "griôs macacoarienses", pois na cultura africana, são aqueles que conhecem e preservam a história e a tradição de seu lugar, através de seu canto, relatam as histórias, as realizações, qualidades mais representativas de uma pessoa, de uma comunidade e de uma sociedade.

${ }^{7} \mathrm{O}$ nome Macacoari é originado da palavra "macaco", por existir tempos atrás grande número desse primata na região. ${ }^{7}$ Quanto à nomenclatura Carmo, sofreu influência do catolicismo, em referência a Nossa Senhora do Carmo. $\mathrm{Na}$ Vila, existe uma festa anual que homenageia Nossa Senhora do Carmo, que se realiza há mais de vinte anos, sempre no dia 16 de julho.
} 
Assim, constatou-se, na Vila do Carmo, duas formas de poder e protagonismo de mulheres negras, olhadas a partir da ótica de gênero, raça e classe, e identificou-se a condição social e muitas intersecções entre elas e que, no mesmo território, as oportunidades eram diferentes. No entanto, ao longo dos 50 anos de liderança à frente da Vila do Carmo, essas diferentes mulheres negras construíram redes de saberes e solidariedade. Para Padinha e Fares (2010, p. 127), "as narrativas permitem decodificar e interpretar as situações que os narradores viveram".

As narrativas das mulheres entrevistadas neste trabalho contam que as histórias da Vila do Carmo do Macacoari sempre giram em torno de nomes das grandes famílias, ocultando as mulheres negras. Essas mulheres estão nesse território desde o século XIX, embora sua descrição seja sempre como uma figura secundária ou, ainda, ligadas às figuras masculinas locais.

Há registros escritos sobre a Vila do Carmo do Macacoari: Fernandes (1993), Atlas (1966), Oliveira (2005), Machado (2006), Oliveira e Furtado (2008) e Machado (2008). Nesses raros registros - devido falta de incentivo e/ou políticas públicas de registro histórico e cultural amapaense - não constam as contribuições das mulheres negras, mesmo sendo elas parte do processo de construção histórica da comunidade. Por isso, este estudo registra memórias e relatos de mulheres negras que nasceram e viveram e têm relação coma Vila do Carmo do Macacoari.

Portanto, para (re)construir a história da Vila do Carmo do Macacoari, não buscamos a perspectiva da história oficial, aquilo que é contado pela história dominante, e sim os relatos expostos pelas mulheres negras idosas, suas memórias cotidianas, seus saberes e seus fazeres. Um exemplo claro são as pessoas lembradas como protagonistas marcantes da Vila do Macacoari nos relatos das entrevistadas: elas mencionam os donos de terras, mas também apontam outras pessoas como protagonistas, pessoas que não eram proprietários, mas pessoas de fundamental importância na construção desse território, inclusive elas próprias.

Desse modo, o presente artigo objetiva compartilhar a Metodologia Pedagogia das Canoas, como possibilidade de (re)construir histórias e memórias esquecidas nas historiografias e (re)contar novas histórias por meio de experiências de vida.

\section{O Rito de Passagem de metodologia a Pedagogia das Canoas}

A Metodologia Pedagogia das Canoas foi o alicerce (o esteio, o assoalho e as paredes) da dissertação de mestrado intitulada "(Re)construindo Caminhos e Histórias de vida de 
Mulheres Negras da Vila do Carmo do Macacoari - Amapá”, na qual se buscou (re)construir o papel de mulheres negras no passado e seu papel no presente na história da Vila do Carmo do Macacoari.

Uma pesquisa qualitativa, de história oral, sob a perspectiva do conceito de experiência do filósofo Walter Benjamim (1987). Para Benjamim, "o que o narrador conta, vem de sua própria experiência ou é contada pelos outros". O autor ainda ressalta que "contar histórias sempre foi a arte de contá-las de novo, e ela se perde quando histórias não são mais conservadas. Ela se perde porque ninguém mais fia ou tece enquanto ouve a história” (BENJAMIN, 1987, p. 205). De acordo com Benjamin, uma história, por mais antiga que seja, se for sempre lembrada, contada, não será esquecida.

A preferência da história oral como metodologia deste estudo se justifica não somente por se realizar em uma região onde os documentos escritos são insuficientes para a fundamentação teórica, mas por considerar que a história oral, enquanto método da pesquisa com base nas reflexões de Neves (2000), nos permitiu dar voz a mulheres negras anônimas esquecidas na historiografia amazônica. Assim como a Pedagogia Crioula, é uma metodologia que traz, em sua origem, a experiência feminina. "Uma delas é o quanto a Pedagogia Crioula tem do jeito, dos fazeres, da participação e da sabedoria das mulheres crioulenses. Portanto, podemos dizer uma pedagogia com essência feminina" (NASCIMENTO, 2017, p. 158).

Durante as entrevistas, utilizamos um questionário semiestruturado abordando: dados gerais da entrevistada; memórias da Vila do Carmo: a infância, a adolescência, o que faziam as famílias das entrevistadas, as práticas agrícolas; e o que foi passado de geração para geração. As memórias da Vila do Carmo também foram buscadas: o processo histórico, seus limites territoriais, os grupos sociais, quando chegaram, onde se instalaram os moradores e o modo de vida da comunidade. Nas memórias, veio à vida das mulheres na Vila do Carmo como utilizavam os recursos naturais, qual era o papel desenvolvido por estas, o que traziam de saberes herdado.

Portanto, foram as narrativas históricas das interlocutoras da pesquisa, as 14 mulheres negras macacoarienses, entre 63 e 102 anos de idade, as "canoas de experiências", que inspiraram a Metodologia de Resgate das Canoas. As entrevistas individuais ocorreram no período de 25 de outubro de 2016 a 21 de abril de 2017 em local escolhido pelas participantes da pesquisa. A escolha dessas mulheres ocorreu por acreditarmos ter sido gerações que viveram ou conviveram com pessoas que presenciaram as transformações da Vila do Carmo e viveram o papel da mulher de ontem e de hoje. São elas: 
Antônia Nery Picanço - filha de Maria Nery de Loureiro Picanço e Benedito do Livramento Picanço - solteira, nasceu, em 25 de maio de 1954, com problemas neurológicos que limitam suas atividades motoras, assim comprometendo suas gesticulações motoras e fala, atualmente mora no Quilombo de Conceição do Macacoari. Antônia Nery tem uma boa memória, pois quando entrevistamos sua mãe Maria Nery de Loureiro, ela estava presente, com alhar atentamente e algumas vezes quando a mãe silenciava, ela lembrava. Perguntamos se gostaria de participar da entrevista e ela abriu um sorriso e disse: "eu quero".

Edmunda Brasão Viégas - filha de Ernestino Borges Picanço Viégas e Angélica Brazão Viégas - irmã de Celina, divorciada, professora primária, lecionou a disciplina Educação para o Lar no ensino fundamental, funcionária federal aposentada, mora em Macapá, mantém vínculo com a Vila do Carmo por laços de parentesco e festividades, nasceu em 4 de novembro de 1937.

Firmina do Rosário Picanço: filha de Joanna Paula do Rosário e João Claudino Afilhado, irmã de Luíza e de Raimunda, viúva, agricultura aposentada, dona de casa, mora em Macapá, mantém vínculo com a Vila do Carmo por laços de parentesco e festividades, nasceu em $1^{\circ}$ de abril de 1932.

Luiza Costa Tolosa Correa - filha de Iria Costa Tolosa Filha e Louriano Rodrigues Albuquerque - irmã de Maria Celina, viúva, pensionista, dona de casa, mora na Vila do Carmo, nasceu em 25 de agosto de 1936.

Luiza do Rosário Almeida - filha de Joana Paula do Rosário Claudino e João Claudino Afilhado - viúva, agricultora aposentada, ocupação dona de casa, mora em Macapá, mas também tem casa na Vila do Carmo, vive entre a capital e a vila, nasceu em 14 de dezembro de 1932.

Maria Ardasse Picanço - filha de Maximino Serra Picanço e Raimunda Maria Ardasse Serra - irmã de Raimunda Ardasse, solteira, técnica em contabilidade, aposentada, dona de casa, emprego informal com vendas de doces e salgados, mora em Macapá, mas ainda mantém vínculo com a Vila do Carmo por laços de parentesco e festividades, nasceu em 26 de janeiro de 1937.

Maria de Jesus Picanço Torrinha - filha de Joaquina Correa Picanço e José Serafim Picanço - casada, pecuarista, professora aposentada, nível superior, mora em Macapá, mas tem casa na Vila do Carmo, vive entre Macapá e a vila, nasceu em 23 de março de 1945. 
Maria Celina Viégas Picanço - filha de Ernestino Borges Picanço Viégas e Angélica Brazão Viégas - casada, professora de $1^{\circ}$ a $8^{\circ}$ ano do ensino fundamental, aposentada, dona de casa, vendas de doces e salgado, emprego informal com vendas de doces e salgados, mora no Quilombo de Conceição do Macacoari, nasceu em 21 de outubro de 1939.

Maria de Lourdes Gonçalves dos Santos - filha de Raimunda Gonçalves e Raimundo Maciel dos Santos casada - agente de saúde, raizeira, mora na Vila do Carmo do Macacoari, nasceu em 10 de março de 1956.

Maria Nair Sousa Costa - filha de Perciliana de Souza Costa e Manoel Pascoal da Costa - viúva, parteira, curandeira, aposentada e do lar, mora na Vila do Carmo, nasceu em 25 de maio de 1941.

Maria Nery de Picanço Loureiro - filha de Antônia Nery da Silva e Benedito Cunha de Loureiro - viúva, pecuarista, aposentada, mora no Quilombo de Conceição do Macacoari, mas ainda mantém vínculo com a Vila do Carmo por laços de parentesco e festividades, nasceu em 24 de outubro de 1915.

Raimunda Ardasse Picanço - filha de Maximino Serra Picanço e Raimunda Maria Ardasse Serra - viúva, agricultura aposentada, dona de casa, diarista, mora na Vila do Carmo, nasceu em 31 de agosto de 1935.

Raimunda do Rosário Sousa - filha de Joana Paula do Rosário Claudino e João Claudino Afilhado - casada, aposentada, dona de casa, mora em Macapá, mantém vínculo com a Vila do Carmo por laços de parentesco e festividades, nasceu em 9 de novembro de 1937.

Sebastiana Albuquerque Costa - filha de Maria Rosária Tolosa Albuquerque e Manoel Santa Rosa de Lima - separada, mas não legalmente, agricultora aposentada, mora em Macapá, mas mantém vínculo com a comunidade de Rio Jordão com parentes, datas festivas e em período eleitoral, nasceu em 7 de julho de 1953.

É pertinente destacar que em cada entrevista realizada, além da atenção para a tonalidade de voz, estávamos atentos para os gestos, o silêncio, os esquivamentos, as meias palavras, o não sei, mesmo sabendo e o olhar para o infinito, tudo isso, em busca da memória de um tempo vivido, a possibilidade de se contar uma nova história. Assim, utilizou-se, como metáfora

o resgate das canoas, uma simbologia para retratar as mulheres negras ribeirinhas macacoarienses e suas sabedorias, neste caso, aqui, representadas 
pelas griôs macacoarienses, ${ }^{8}$ mulheres da vila que, até então, ninguém havia ido a seu encontro para escutar suas experiências. Assim como canoas que ficam à deriva no rio, elas estavam cheias de preciosidades à espera de alguém para resgatá-las, e este trabalho propõe-se a isso. (ALMEIDA, 2018, p. 164).

Uma metodologia amazônica, uma vez que foi pensada para desvelar o protagonismo de mulheres negras anônimas das águas, dos campos e das florestas amazônicas. Lideranças comunitárias que, ao longo dos anos, vêm resistindo nesses territórios, construindo alternativas coletivas para enfrentar: o racismo, o machismo e o sexismo. E, ainda, lutar para manter a floresta de pé e preservar os saberes ancestrais das mulheres negras impactados por grandes projetos de desenvolvimento para a Amazônia.

Uma metodologia a qual se teve, neste trabalho, a "ousadia" de chamar de "Pedagogia das Canoas", um encontro de experiências, por ser muito além de um percurso metodológico e também ser transgressora, pois possibilitou a construção coletiva e o ecoar de outras vozes, para além da pesquisadora, e, com isso, o surgimento de novas histórias. "Cada história é o ensejo de uma nova história, que desencadeia uma outra, que traz uma quarta, etc." (BENJAMIN, 1987, p. 13), e, consequentemente, a transformação social do lugar. “Os beneficiários da pesquisa são, portanto os membros da própria comunidade” (BARBIER, 2007, p. 61).

A Pedagogia das Canoas segue o rigor científico, mas, por outro lado, tem características próprias, centradas no acolhimento, perpassando por quatro premissas: o zelo, o respeito, a escuta ativa e o afeto. Optou-se pelo zelo como alicerce pelo fato de as interlocutoras da pesquisa serem mulheres na faixa etária de 63 a 102 anos. Em vista disso, todo o percurso metodológico foi pensado com cuidado, a partir das interlocutoras e para elas, ao mesmo tempo, que se atendessem os objetivos do estudo e garantisse a autonomia das interlocutoras e da pesquisadora.

De acordo com Freire (1996, p. 66), "o respeito à autonomia e a dignidade de cada um é um imperativo ético e não um favor que podemos ou não conceder uns aos outros". Nesse sentido, desde o primeiro contato com as interlocutoras da pesquisa, procurou-se respeitar suas histórias de vida, suas individualidades, suas necessidades e suas disponibilidades para conceder entrevistas.

Outro detalhe importante, procurou-se realizar um trabalho refinado de escuta ativa. Para isso, partiu-se das narrativas históricas das interlocutoras como ponto inicial para as

\footnotetext{
${ }^{8} \mathrm{Na}$ cultura africana, são aqueles que conhecem e preservam a história e a tradição de seu lugar, através de seu canto, relatam as histórias, as realizações, qualidades mais representativas de uma pessoa, de uma comunidade e de uma sociedade (ALMEIDA, 2018).
} 
reflexões da dissertação, todo o protagonismo expressado por elas. Para Barbier (2007, p. 94), “a escuta sensível apoia-se na empatia," ou seja, o pesquisador deve se colocar no lugar de seu interlocutor para compreender todas suas formas de linguagens e simbologias.

É importante salientar que o silêncio foi fundamental para buscar respostas dos problemas da pesquisa. Foi necessário silenciar a "voz" do/a pesquisador/a, interiormente, para mergulhar no mundo das narrativas das interlocutoras, ocorrendo o encontro de almas entre a pesquisadora e as interlocutoras, para que pudessem ouvir e compreender a outra e também compreender o que os seus ouvidos captaram, conseguindo, assim, ouvir a si mesmas, para, em seguida, expor suas ideias, as quais se traduziram em escuta ativa e silenciosa.

No processo de fala e da escuta a disciplina do silêncio a ser assumido é um rigor e a seu tempo pelos sujeitos que falam e escutam é um "sine qua" da comunicação dialógica. O primeiro sinal de que o sujeito que fala sabe escutar é a demonstração de sua capacidade de controlar não só a necessidade de dizer a sua palavra, que é direito, mas também o gosto pessoal, profundamente respeitável, de expressá-la (FREIRE, 1996, p. 131).

Ainda segundo Freire (1996, p.135), “a verdadeira escuta não diminui em mim, em nada, a capacidade de exercer o direito de discordar, de me opor, de me posicionar. Pelo contrário, é escutando bem que me preparo para melhor me colocar ou melhor me situar do ponto de vista das ideias". Ao trazer consigo esse pensamento, o pesquisador terá facilidade em fazer as análises dos resultados de sua pesquisa.

Saliente-se ainda que, além de ecoar outras vozes, a escuta ativa permitiu identificar diferentes linguagens: da solidariedade, do partilhar, do compartilhar, da dor, do gosto, da alegria, da tristeza, do silêncio, do medo, do poder. Enfim, analisar, nas entrelinhas das narrativas, as linguagens corporal, falada e escrita e suas convergências e divergências sobre o mesmo contexto.

Diante disso, pode se considerar a escuta ativa e silenciosa como a premissa mais complexa dessa Pedagogia das Canoas, uma vez que a pesquisadora, mesmo engajada na pesquisa, precisa manter a autocrítica, evitando a prevalência das emoções, e focar a ideia central da pesquisa.

Os autores, Barbier (2007) e Hooks (2017) concordamos que pesquisar e educar têm que dar prazer, contentamento e envolvimento coletivo. A Pedagogia das Canoas abre espaço para uma pesquisa engajada e educativa. Em sua elaboração, envolveram-se vários conhecimentos e sentimentos. 
A Pedagogia das Canoas, encontro de experiências, pelo fato de ter forte relação com as experiências vividas no passado, abarca, entre suas premissas, o afeto, pois torna possível recuperar memórias de infância, memórias ancestrais e memórias coletivas de povos e comunidades tradicionais.

Segundo Magalhães (2002, p. 56), a memória é, então, crucial como meio e processo para provocar e (re)construir as articulações entre o passado e o presente, entre o indivíduo e o social. Magalhães (2002, p. 56) considera, ainda, "as imagens do passado reduzem no presente e relampejam porque o passado não está morto, inerte". Enfatize-se que o êxito desse encontro dependerá do cuidado do pesquisador na construção de sua metodologia.

A Pedagogia das Canoas permitiu resgatar, do passado, sujeitos excluídos das historiografias - as mulheres negras macacoarienses - torná-los, no presente, sujeitos protagonistas, e, assim, (re)contar novas histórias a partir de experiências do tempo vivido pelas interlocutoras da pesquisa.

Além disso, permitiu trabalhar a etnografia e a memória histórica conjuntamente e acolher diferentes visões de mundo sobre o mesmo contexto. Para isso, suas experiências, a ligação afetiva e o amor das interlocutoras pelo lugar de estudo foi fundamental para entrelaçar a história ao espaço do local da pesquisa. Para Tuan (2012, p. 152), o elo afetivo entre a pessoa e o lugar chama-se topofilia. O mesmo autor afirma que:

O meio ambiente natural e a visão do mundo estão estreitamente ligadas: a visão do mundo, se não é derivada de uma cultura estranha, necessariamente é construída dos elementos conspícuos do ambiente social e físico de um povo. (TUAN, 2012, p. 116).

Corroboramos com Tuan (2012) porque, nas narrativas das interlocutoras da pesquisa, os diferentes modos de olhar a história local estão intrinsicamente ligados ao ambiente. Para elas, além de ser um espaço geográfico que agrega pessoas, é um espaço sagrado, porque une as pessoas em torno de uma herança cultural e das recordações no qual expressam o modo de vida local, sua identidade.

\section{Caminho percorrido: na (re)construção das canoas, no contar e ouvir, no contar e cantar, na reconstituição da sabedoria e no recontar novas histórias}

Este tópico se reporta a descrever o caminho percorrido para estruturar as seis fases da metodologia e suas interfases. Poderíamos dizer que antecede à própria pesquisa, no momento 
em que se identificou as interlocutoras do estudo. Neste artigo, essas fases são descritas a seguir e são: na (re)construção das canoas - a identificação das interlocutoras; no contar e ouvir; no contar e cantar; na arte de cantar e contar; na reconstituição da sabedoria; e no recontar novas histórias.

Na fase 1 - na (re)construção das canoas: a identificação das interlocutoras da pesquisa, será discutido como se identificou as mulheres negras interlocutoras da pesquisa de mestrado. Primeiramente, elas participaram de entrevistada do trabalho de campo da disciplina Sistemas Agrícolas Tradicionais do Mestrado Profissional em Sustentabilidade junto a Povos e Territórios Tradicionais (MESPT), $3^{\mathrm{a}}$ turma, Universidade de Brasília (UnB), sobre as práticas agrícolas das mulheres na Vila do Carmo do Macacoari.

Para isso, adotaram-se alguns critérios: ser mulher com a faixa etária mínima de 60 anos; ter morado e ter convivido com mulheres detentoras de conhecimentos tradicionais da Vila do Carmo; e, de alguma forma, ter contribuído para a história e a memória da vila. ${ }^{9}$ Por isso, nesta pesquisa, denominamos essas mulheres de griôs macacoarienses. ${ }^{10}$

A ideia foi buscar, no mínimo, seis mulheres, como recomendava o trabalho da disciplina, das primeiras famílias que se estabeleceram no território do Carmo do Macacoari e que tivessem praticado atividades com saberes e práticas tradicionais. Assim, conversou-se pessoalmente com cada uma das seis mulheres.

Durante as entrevistas, utilizou-se um questionário semiestruturado, ${ }^{11}$ com cinco eixos sobre as memórias da Vila do Carmo do Macacoari. No entanto, confiou-se na memória de infância para iniciar o diálogo, como possibilidade de encontrar, no passado, possíveis respostas às indagações do presente.

Diante desses dados pré-coletados, ${ }^{12}$ ampliou-se o número de interlocutoras, chegando a 14 mulheres negras com idade de 63 a 102 anos, que, posteriormente, passaram a ser as interlocutoras da pesquisa. São, em grande parte, as últimas remanescentes da $2^{\mathrm{a}}$ e $3^{\mathrm{a}}$ gerações de mulheres negras da Vila do Carmo do Macacoari, entre elas, a mãe, as tias e outras da

\footnotetext{
${ }^{9} \mathrm{Na}$ disciplina, objetivo foi identificar as práticas agrícolas das mulheres Vila do Carmo do Macacoari, para averiguar de que maneira a comunidade desenvolvia no passado suas práticas agrícolas e quais eram as tarefas desenvolvidas pelas mulheres nessa prática. E de que modo suas mães e avós também desenvolviam suas práticas agrícolas e as relacionavam com outros saberes (ALMEIDA, 2018, p. 52).

${ }^{10}$ As detentoras de conhecimentos tradicionais e da história da Vila do Carmo do Macacoari.

11 ALMEIDA, 2018, p. 201. Ver Apêndice 1 -. Roteiro semiestruturado aplicado na entrevista individual. Disponível em: http://repositorio.unb.br/handle/10482/34042. Acesso em: 26 mar. 2019.

${ }^{12}$ Esses dados serviram para a produção do pôster tendal de conhecimentos das mulheres do Carmo do Macacoari na década de 1950 da disciplina Sistema Agrícolas Tradicionais e posteriormente para análise da pesquisa. (ALMEIDA,2018). Disponível em: http://repositorio.unb.br/handle/10482/34042. Acesso em: 26 mar. 2019.
} 
vivência da pesquisadora, guardiãs da memória histórica da fundação da vila e de seus primeiros moradores.

$\mathrm{Na}$ fase 2 - no contar e ouvir: a entrevista, que significa "escutá-las durante as entrevistas", abordar-se-á como se realizaram as entrevistas, os cuidados e dificuldades para realizá-las e como as fontes orais se tornaram documento oral de pesquisa.

As entrevistas individuais ocorreram no período de 25 de outubro de 2016 a 21 de abril de 2017, tendo, como suporte, o roteiro semiestruturado. Foram realizadas pela pesquisadora, com auxílio de uma assistente voluntária de fotografia e filmagem.

Os autores Meihy e Holanda (2015) afirmam que o epicentro da pesquisa com a história oral se acha na concepção das entrevistas e na condição para sua realização e em um conjunto de pessoas disponíveis para serem entrevistadas.

Concordando com os autores, a pesquisadora tomou o cuidado de informar, a cada uma das entrevistadas, que estava indo ao seu encontro para entrevistá-las. Normalmente em locais onde elas se sentiam mais à vontade para falar, preferencialmente, suas casas. Fase esta que requereu muita paciência, porque algumas conversas agendadas foram remarcadas por mais de uma vez, em razão da necessidade emergente das entrevistadas.

Na fase 3 - no contar e cantar: a roda de conversa território de memória, falar-se-á da interfase sensibilização (de como as mulheres negras que concederam a entrevista individual a participar da pesquisa), da interfase preparação (passo a passo para a organização da Roda de Conversa Território de Memórias) e da interfase descrição (passo a passo da Roda de Conversa Território de Memória).

Como mencionado anteriormente, o estudo teria como interlocutoras mulheres negras acima de 60 anos. A questão era como convencê-las a participar. Para isso, contatou-se cada uma delas para convidá-las a participar da Roda de Conversa Território de Memória. Pois, já havia se percebido qual atividade da disciplina contribuiu para a sensibilização, e elas se sentiram valorizadas e perceberam o quanto suas memórias eram valiosas.

Logo, para convencê-las, uniu-se esse sentimento com a importância de elas serem as últimas remanescentes da segunda e da terceira gerações de macacoarienses, bem como com o quanto suas memórias eram importantes e precisavam ser registradas tanto para o presente quanto para as futuras gerações.

No início de agosto de 2017, consultaram-se, novamente, as potenciais participantes, para agendar os dias do encontro. Nas conversas, falou-se sobre fatores limitantes, os feriados 
santos e as festas de santo,13 e acordaram-se os dias 14 e 15 de setembro de 2017 para a realização da roda de conversa.

$\mathrm{Na}$ interfase preparação da Roda de Conversa Território de Memórias, traçou-se a metodologia utilizada no encontro coletivo: o pensar fazer - roteiro orientador, programação, desenho da roda, crachás e material didático -; e a logística - local da oficina, transporte, alimentação e contatos com a equipe de apoio.

O primeiro passo foi pensar no roteiro semiestruturado como instrumento metodológico a ser aplicado na roda de conversa e como esquematizá-lo, tendo como ponto de partida as entrevistas individuais, no sentido de elaborar questões que tanto complementassem o documento oral quanto aprofundassem o protagonismo da mulher negra na Vila do Carmo do Macacoari.

Subdividiu-se o roteiro semiestruturado no que se chamou de três tempos: o tempo, lugar e memórias de mulheres negras - os saberes; o tempo, lugar e memórias de mulheres negras - ser mulher negra; e o tempo, lugar e memórias de mulheres negras - o território, heranças dos saberes, na (re)construção das canoas. Cada tempo desdobrado em perguntas, no sentido de captar durante a conversa as experiências vividas na Vila do Carmo do Macacoari pelas mulheres negras.

O segundo passo foi a criação de três paródias, o que chamamos de três músicas ("É bem aqui no Carmo do Macacoari”, "Eu vim de lá, eu vim de lá pequenininha" e "Eu fui embora meu amor chorou")14 com o intuito de dinamizar o encontro, chamar a atenção das participantes para determinadas atividades e inspirar as conversas.

O terceiro passo, a partir do roteiro semiestruturado, foi a concepção da programação norteadora, para dois dias de atividades da Roda de Conversa Território de Memórias. Pensouse em um momento criativo, por meio de dinâmicas, músicas e outras formas de dinamização que, ao mesmo tempo, atendesse à expectativa de suas participantes, bem como às suas limitações.

Ao quarto passo, chamou-se de zelo, no qual se planejou a logística para acolher as interlocutoras da pesquisa, do trajeto até a vila, passando por sua estadia durante três dias, até o seu retorno: a ida, a chegada à vila, a hospedagem, o local do encontro, a saúde das participantes, a alimentação, o lazer e o retorno daquelas que não moram na vila.

\footnotetext{
${ }^{13}$ Festividades que celebram santos católicos, com festas e rezas.

14 ALMEIDA, 2018, p. 64. Ver Quadro 1 - As músicas Apêndice 1. Disponível em: http://repositorio.unb.br/handle/10482/34042. Acesso em: 26 mar. 2019.
} 
$\mathrm{O}$ zelar foi a palavra de regra. Para cumpri-la, recorreu-se à rede de amigos e familiares. Vale ressaltar que estar preparado financeiramente ou instituir parceiras para realizar atividades dessa natureza é fundamental.

O quinto passo foi a confecção do crachá. A ideia surgiu com a produção dos convites, com o intuito de identificar participantes da roda e criar uma recordação simbólica a ser conservado. Foram produzidos em papel Panamá, decorado com tecido de algodão cru, com arremates de tecidos coloridos, gregas de algodão e viés de diversas cores, bem como barbante de algodão. Eles foram utilizados porque a equipe de trabalho não conhecia todas as mulheres.

$\mathrm{Na}$ interfase - na arte de cantar e contar: os três tempos da roda de conversa território de memória, busca-se discorrer sobre a sistematização da Roda de Conversa Território de Memórias, tomando, como base, o roteiro semiestruturado específico - os três tempos e a programação do encontro.

A Roda de Conversa Território de Memórias foi planejada para 14 mulheres negras, com idade de 63 a 102 anos de idade, descendentes de famílias de criadores de gado e de famílias de roceiros do local de estudo. A partir do roteiro de entrevista, foi construída a programação norteadora, 15 com carga horária de 16 horas-aula, ou melhor, em dois dias, sendo facilitada pela pesquisadora, com apoio de uma equipe técnica: uma animadora, uma relatora, uma fotógrafa e um cinegrafista. Todos os momentos foram filmados e fotografados, para posterior análise.

O espaço foi organizado com cadeiras em semicírculo, caixa amplificada, microfones, filmadora e gravador de voz e quatro mesas pequenas com cadeiras, cobertas com papéis, sobre eles: tintas de cores várias de tecido, borrachas, pincéis de pelo de vários tamanhos, canetas para tecido de cores variadas, lápis preto, canetas e um copo d'água (para lavar os pincéis).

Como mencionado anteriormente, a facilitação do encontro teve, como apoio, o roteiro semiestruturado - os três tempos:16 o tempo, lugar e memórias de mulheres negras - os saberes; o tempo, lugar e memórias de mulheres negras - ser mulher negra; e o tempo, lugar e memórias de mulheres negras - o território.

Primeiramente, o tempo, lugar e memórias de mulheres negras - os saberes, com os seguintes eixos norteadores: "Quais eram as atividades praticadas pelas mulheres negras da Vila do Carmo do Macacoari? Quais eram os locais que desenvolviam essas práticas (saberes)?

15 ALMEIDA, 2018, p. 201. Ver Apêndice 3 - A programação da roda de conversa. Disponível em: http://repositorio.unb.br/handle/10482/34042. Acesso em: 26 mar. 2019.

${ }^{16}$ Disponível em: http://repositorio.unb.br/handle/10482/34042. Acesso em: 26 mar. 2019. 
Quais saberes você herdou de outras mulheres negras do Carmo? Quais você ainda pratica? Por que você ainda pratica? Você acha que os saberes das mulheres mais velhas do Carmo estão sendo guardadas? Como você transmite seus saberes? E para quem você transmite? E por que você transmite? Qual a sua contribuição para a comunidade hoje?"

Na sequência, na conversa sobre o tempo, lugar e memórias de mulheres negras - os saberes, antes de iniciar, a conversa, que teve a duração de aproximadamente 40 minutos, as participantes cantaram a música "É bem aqui no Carmo do Macacoari”.

Logo depois, orientou-se as participantes para a produção do mapa dos saberes no território, dizendo para elas desenharem os locais de seus saberes a partir de suas antigas casas. Explicou-se que cada uma receberia um pedaço de tecido de algodão cru medindo $32 \mathrm{~cm} \times 30$ cm, debruado com tecido de chitão de borda amarela. Nele, desenhariam suas memórias e, ao término da atividade, retornariam ao círculo para socializar.

O tempo, lugar e memórias de mulheres negras - ser mulher negra teve, como eixos norteadores: "Como você se via e sentia como uma mulher negra na Vila do Carmo do Macacoari? Havia discriminação? Se passou, como se viu nessa situação? Como era relação entre as mulheres negras? Como era relação das mulheres negras com as mulheres não negras? E, hoje, como você se sente como mulher negra na Vila do Carmo do Macacoari?"

Após a conversa, foram orientadas para a produção do segundo mapa: ser mulher negra na Vila do Carmo, debruado por tecido de chita estampado de cor azul.

No tempo, lugar e memórias de mulheres negras - o território, heranças dos saberes, no resgate das canoas, no início cantou-se a música "Eu fui embora meu chorou”. Narrou-se a história dos "Resgates das canoas", ir ao encontro das canoas para trazer à reflexão a continuidade dos saberes e fazeres de mulheres negras da Vila do Carmo do Macacoari.

As interlocutoras falaram sobre "Como era a vida e a Vila do Carmo do Macacoari e quem eram seus moradores? Todas as pessoas eram donas de suas terras? Por que, mesmo sendo uma comunidade fundada por negros, o Carmo não solicitou o processo para se reconhecer como quilombola? Qual foi sua maior contribuição para a Vila do Carmo? E o que liga você à Vila do Carmo?"

Prosseguindo, foram distribuídos novamente pedações de tecidos de algodão cru, debruado, dessa vez, de chita na cor rosa, para que, através de desenhos, simbolizassem "Como eu mulher negra do Carmo do Macacoari estou transmitindo meus conhecimentos, e para quem? E como estou transmitindo?" 
Por conseguinte, seguiu-se para a fase 5 - na reconstituição da sabedoria, a recuperação da memória histórica por meio dos mapas dos territórios (desenhos) e do documento oral oriundo das entrevistas, que, para Neves (2000), além de fundamentar o historiador, preserva a memória individual do entrevistado. Recuperou-se também os raros documentos identificados no período de outubro de 2016 a maio de 2018.17

O levantamento documental foi realizado em páginas web e órgãos públicos, nas cidades de Macapá e Belém. Igrejas, cartórios e arquivos de cemitérios18 também foram visitados para ajudar na reconstituição da história da vila e das mulheres negras.

No entanto, três locais foram fundamentais para essa reconstituição: o primeiro, as casas dos antigos moradores; o segundo, em cemitérios da Vila do Carmo, de Macapá e de Belém; e o terceiro, os acervos da Igreja Matriz de São José de Macapá.

De posse de documentos, seguiu-se para a fase final da Pedagogia das Canoas: no recontar novas histórias, a análise dos dados.

A metodologia se finaliza com a fase 6 - no recontar novas histórias: análise dos dados. Abordar-se-á como se realizaram as Análise e discussão dos resultados. Salienta-se que dados analisados foram: as narrativas das entrevistadas (documento oral), em conformidade com os mapas dos territórios (resultado da roda de conversa), em consonância com os documentos (fotografias, registros de nascimentos, entre outros) e as referências bibliográficas referentes ao tema e reflexões da pesquisadora, possibilitando, assim, recontar-se novas histórias do protagonismo de mulheres negras da Vila do Carmo do Macacoari.

\section{Considerações finais}

Consideramos esse trabalho muito relevante para a ciência, academia e sociedade em geral, pois traz ricas informações e relatos de vida das mulheres negras amapaenses, que são protagonistas de uma história magnífica e rica em conhecimentos amazônicos, possibilitamos a elas não só a oportunidade de fala, mas também de serem ouvidas por outras pessoas.

Ter o registro oral em documento para pesquisa é de grande relevância, já que agora não estarão apenas nas memórias dessas mulheres, correndo o risco de serem perdidos no tempo. Assim damos visibilidade a essas griôs, que, apesar de saberem das inúmeras atividades que desenvolveram, desconheciam a sua importância na construção da Vila do Carmo do

\footnotetext{
${ }^{17}$ No mesmo período, realizou-se o levantamento bibliográfico referente ao tema do estudo.

${ }^{18}$ ALMEIDA, 2018, p. 88-90. Ver Quadro 2 - Caminho da pesquisa: órgãos e entidades visitadas. Disponível em: http://repositorio.unb.br/handle/10482/34042. Acesso em: 26 mar. 2019.
} 
Macacoari e de seus ensinamentos para gerações futuras, através dos saberes e fazeres tradicionais desempenhados por elas.

Estudar mulheres negras na Amazônia sempre foi um desafio, devido à escassez de pesquisas nessa temática, considerando a invisibilidade dessas mulheres diante da história oficial. No entanto, o contar a história da Vila do Carmo do Macacoari sob o olhar das mulheres negras foi um desafio ainda maior, pois se trata de uma pequena localidade. Apesar de existir desde o século XIX, ter contribuído com a economia e a cultura do estado do Amapá, os estudos científicos sobre essa comunidade são ínfimos. O desejo é que este estudo possa despertar o interesse em outros pesquisadores sobre a temática da mulher negra amazônica do Amapá.

É preciso ressaltar que as poucas documentações relacionadas a sua ocupação se perderam com o tempo ou estão em mãos de descendentes dos primeiros moradores, os quais não tivemos acesso. Para este estudo, além da ausência de documentos surgiram outros obstáculos, os questionamentos dos motivos de estudar um lugar onde as fontes documentais são raríssimas e ninguém sabe se existe.

O estudo mostrou que ao olhar e ouvir as mulheres negras da Vila do Carmo do Macacoari pelas lentes das griôs retiramos a invisibilidade da mulher negra na Amazônia e (re)construímos sua contribuição para a historiografia. São sujeitos sociais invisíveis tanto do ponto de vista de seu protagonismo como de sua diversidade e de suas mazelas sociais, muitas causadas pela ausência de políticas públicas. O estudo mostrou que, a partir do documento oral produzido, a Vila do Carmo é uma comunidade negra ribeirinha descendente de escravizados, negros livres e mestiços.

Decidiu-se compartilhar a Pedagogia das Canoas como uma possibilidade de (re)construir histórias e memórias esquecidas nas historiografias e (re)contar novas histórias, a partir de experiências de vida, porque se acredita que a confiabilidade e a boa qualidade de uma pesquisa científica estão relacionadas à metodologia adotada pelo pesquisador. Por se acreditar, também, que as metodologias de abordagem qualitativas podem ser instrumentos de transformações de realidades locais quando bem formuladas e aplicadas.

Então, com a Pedagogia das Canoas, além de ser um encontro de experiências, verificou-se que era possível combinar a criatividade (ficção) e o rigor acadêmico (o percurso metodológico - o caminho a ser percorrido pelo pesquisador na tentativa coletar dados para pesquisa). Assim, ao contextualizar e descrever o percurso metodológico, procurou-se demonstrar que uma metodologia não é uma "camisa de força", no sentido de limitar a 
capacidade criadora do pesquisador ao rigor acadêmico, ela pode ser uma atividade prazerosa, criativa e científica.

Reportando-se, portanto, essa metodologia a outros estudos científicos cujos objetivos sejam de reconstruir a memória histórica, pois, com ela, conseguiu-se buscar fragmentos esquecidos ao longo das historiografias, levando, dessa forma, o pesquisador a dialogar com outros campos das ciências humanas e sociais.

Acredita-se, portanto, que a Pedagogia das Canoas pode contribuir na preservação da memória de grupos, povos e comunidades tradicionais excluídos das historiografias, pela sua capacidade de envolver diferentes grupos de pessoas. Por sua vez, a roda de conversa é um espaço participativo "mágico", de circularidade energética, em que cada integrante tem a liberdade para emitir sua opinião sobre o tema debatido igualmente, além de promover reflexões e aprendizados.

Por outro lado, os mapas dos territórios e o documento oral foram ferramentas essenciais para acolher as diferentes formas identitárias de pertencimento de cada uma das interlocutoras sobre o local de estudo. Assim, foi possível desvelar e confirmar cientificamente que, na Amazônia, existiram mulheres negras que comandaram por mais de 50 anos a Vila do Carmo do Macacoari e que esta localidade foi criada no final do século XIX, entre outras descobertas.

Assim, precisa-se estar atento para conhecer as potencialidade e limitações dos possíveis interlocutores da pesquisa, para que diante da aplicabilidade da metodologia não ocorram resistências, a exemplo, a produção dos mapas dos territórios. Portanto, é uma pedagogia transformadora, de acolhimento e coletiva, uma vez que, para sua execução, necessitou-se constituir uma equipe de trabalho para que todo o processo dinâmico desta pesquisa fosse realizado.

\section{REFERÊNCIAS}

ALMEIDA, Maria das Dores do Rosário. (Re)construindo caminhos e histórias de mulheres negras da Vila do Carmo do Macacoari - Amapá. 2018. Dissertação (Mestrado em Desenvolvimento Sustentável junto aos Povos e Terras Tradicionais) - Centro de Desenvolvimento Sustentável, Universidade de Brasília (UnB), Brasília, 2018. Disponível em: http://repositorio.unb.br/handle/10482/34042. Acesso em: 26 mar. 2019.

ATLAS DO AMAPÁ. Território Federal do Amapá. Instituto Regional de Desenvolvimento do Amapá - Conselho Nacional de Geografia - IBGE, 1966. 
BARBIER, Renée. A pesquisa-ação. Tradução Lucie Didio. Brasília: Líber Livro, 2007.159 p. (Série Pesquisa, v. 3).

BENJAMIN, Walter. Magia e técnica, arte e política: ensaios sobre literatura e história da cultura. Obras escolhidas v. I. São Paulo: Editora Brasiliense, 1987. 253 p.

FERNANDES, Marcus Emanuel Barroncas. New field records of night monkeys, genus Aotus, in northern Brazil. Neotropical primates, v. 1, n. 4, p. 35, dez. 1993. Disponível: <http://static1.1.sqspcdn.com/static/f/1200343/18197314/1337025496837/NP1.4.pdf?token= HjC\%2BUfT3\%2BdI017ZuqpKE9BaX\%2BvI\%3D>. Acesso em: 15 maio 2016.

FREIRE, Paulo. Pedagogia da autonomia: saberes necessários à prática educativa. 20. ed. São Paulo: Paz e Terra, 1996. (Coleção Leitura).

HOOKS, Bell. Ensinado a transgredir: a educação como prática da liberdade. Tradução Marcelo Brandão Cipolla. 2. ed. São Paulo: WMF Martins Fontes, 2017.

LE GOFF, Jacques. História e memória. 7. ed. rev. Campinas: Editora Unicamp, 2013.

MACHADO, Ruancarlo D’Almeida. A festa de São Sebastião no Carmo do Macacoari: Como um espaço de religiosidade e cultura popular. 2006. $83 \mathrm{f}$. Trabalho de conclusão de curso (História)-Faculdade de Macapá - FAMA, Amapá, 2006.

MACHADO, Danusa da Silveira. Os impactos ambientais da bubalinocultura no igarapé do Braço. p. 71. Monografia Apresentada a Fim de Adquirir o Título de Pós Graduada em Pericia e Auditoria Ambiental pela Faculdade de Macapá - FAMA, Amapá, 2008.

MAGALHÃES, Nancy Alessio. Narradores: vozes e poderes de diferentes pensadores. Revista História Oral, São Paulo, n. 5, p. 45-70, 2002.

MEIHY, José Carlos Sebe Bom; HOLANDA, Fabíola. História oral: como fazer, como pensar. 2. ed. 4. imp. São Paulo: Editora Contexto, 2015. 175 p.

NASCIMENTO, Márcia Jucilene do. Por uma pedagogia crioula: memória, identidade e resistência no quilombo de conceição das crioulas - Pernambuco. 2017. Dissertação (Mestrado em Desenvolvimento Sustentável junto aos Povos e Terras Tradicionais) - Centro de Desenvolvimento Sustentável, Universidade de Brasília, Brasília, 2017. Disponível em: http://repositorio.unb.br/bitstream/10482/31319/1/2017_M\%c3\%a1rciaJucilenedoNascimento .pdf. Acesso em: 26 mar. 2019.

NEVES, Lucilia de Almeida. Memória, história e sujeito: substratos da identidade. Revista História Oral, São Paulo, n. 3, p. 109-115, 2000.

OLIVEIRA, Maria do Socorro dos Santos. A comunidade de Conceição do Macacoari: relatório antropológico apresentado ao Instituto nacional de colonização e reforma agrária. Macapá: Fundação Universidade Federal do Amapá, jun. 2005. 
OLIVEIRA, Neucirene Almeida; FURTADO, Milena. Relatório mulher teu corpo a ti pertence: uma abordagem da Lei Maria da Penha. Macapá: Instituto de Mulheres Negras do Amapá - IMENA, set. 2008. 179 p.

PADINHA, Maria do Socorro Ribeiro; FARES, Josebel Akel. Narrativas orais, educação e memória. In: Coelho, Wilma de Nazaré Baia (Org.). Educação e relações raciais: conceituação e historicidades. São Paulo: Livraria da Física, 2010. (Coleção da Ciência).

TUAN, Yi-Fu. Topofilia: um estudo da percepção, atitudes e valores do meio ambiente. Tradução Lívia de Oliveira. Londrina: Eduel, 2012. 342 p.

\section{SOBRE OS AUTORES:}

\section{Maria das Dores do Rosário Almeida}

Mestra em Desenvolvimento Sustentável junto aos Povos e Terras Tradicionais pela Universidade de Brasília (UnB). Militante do Movimento de Mulheres Negras Brasileira (AMNB). Ambientalista. Cofundadora do Instituto de Mulheres Negras do Amapá (IMENA) e Rede Fulanas - Negras da Amazônia Brasileira (NAB). E-mail: mulheresdoigarape@ gmail.com (iD http://orcid.org/0000-0002-9994-7952

\section{Elivaldo Serrão Custódio}

Doutor em Teologia pela Faculdades EST, São Leopoldo-RS. Pós-doutor em Educação pela Universidade Federal do Amapá (UNIFAP). Professor Permanente no Programa de PósGraduação em Educação da UNIFAP. Vice Líder do Grupo de Pesquisa Educação, Interculturalidade e Relações Étnico-Raciais (UNIFAP/CNPq). E-mail: elivaldo.pa@hotmail.com

iD http//orcid.org/0000-0002-2947-5347 